\title{
Ecological consequences of anomalies in atmospheric moisture and snowpack
}

\author{
Aaron N. Johnston DD,${ }^{1,2,10}$ Jason E. Bruggeman, ${ }^{3,4}$ Aidan T. Beers (iD, ${ }^{5,6,7}$ Erik A. Beever (D), 1,8 \\ Roger G. Christophersen, ${ }^{9}$ And Jason I. Ransom ${ }^{9}$ \\ ${ }^{1}$ U.S. Geological Survey, Northern Rocky Mountain Science Center, 2327 University Way, Suite 2, Bozeman, Montana 59715 USA \\ ${ }^{2}$ School of Environmental and Forest Sciences, University of Washington, Seattle, Washington 98195 USA \\ ${ }^{3}$ Beartooth Wildlife Research, 4157 West 145th Street, Savage, Minnesota 55378 USA \\ ${ }^{4}$ Department of Fisheries, Wildlife, and Conservation Biology, University of Minnesota, 200 Hodson Hall, 1980 Folwell Avenue, \\ St. Paul, Minnesota 55108 USA \\ ${ }^{5}$ Department of Ecology and Evolutionary Biology, University of Colorado Boulder, 1900 Pleasant Street, UCB 334, Boulder, \\ Colorado 80302 USA \\ ${ }^{6}$ Institute of Arctic and Alpine Research, University of Colorado Boulder, UCB 450, Boulder, Colorado 80309 USA \\ ${ }^{7}$ Department of Wildland Resources, Utah State University, 5230 Old Main Hill, NR 206, Logan, Utah 84322 USA \\ ${ }^{8}$ Department of Ecology, Montana State University, P.O. Box 173460, Bozeman, Montana 59717 USA \\ ${ }^{9}$ National Park Service, North Cascades National Park Service Complex, 810 State Route 20, Sedro Woolley, Washington 98284 USA
}

Citation: Johnston, A. N., J. E. Bruggeman, A. T. Beers, E. A. Beever, R. G. Christophersen, and J. I. Ransom. 2019. Ecological consequences of anomalies in atmospheric moisture and snowpack. Ecology 100(4):e02638. 10.1002/ecy.2638

Abstract. Although increased frequency of extreme-weather events is one of the most secure predictions associated with contemporary climate change, effects of such events on distribution and abundance of climate-sensitive species remain poorly understood. Montane ecosystems may be especially sensitive to extreme weather because of complex abiotic and biotic interactions that propagate from climate-driven reductions in snowpack. Snowpack not only protects subnivean biotas from extreme cold, but also influences forage availability through timing of melt-off and water availability. We related relative abundances of an alpine mammal, the American pika (Ochotona princeps), to measures of weather and snowpack dynamics over an 8-yr period that included before and after a year of record-low snowpack in Washington, USA. We sought to (1) quantify any change in pika abundance associated with the snowpack anomaly and (2) identify aspects of weather and snowpack that influenced abundance of pikas. Pikas showed a 1-yr lag response to the snowpack anomaly and exhibited marked declines in abundance at elevations below 1,400 m simultaneous with increased abundances at higher elevations. Atmospheric moisture, indexed by vapor pressure deficit (VPD), was especially important, evidenced by strong support for the top-ranked model that included the interaction of VPD with snowpack duration. Notably, our novel application of VPD from gridded climate data for analyses of animal abundances shows strong potential for improving species distribution models because VPD represents an important aspect of weather that influences the physiology and habitat of biota. Pikas were apparently affected by cold stress without snowpack at mid elevations, whereas changes to forage associated with snowpack and VPD were influential at high and low elevations. Our results reveal context dependency in pika responses to weather and illustrate how snow drought can lead to rapid change in the abundance of subnivean animals.

Key words: alpine ecosystem; American pika; climate change; extreme weather; Ochotona princeps; phenology; snow drought; vapor pressure deficit.

\section{INTRODUCTION}

Ecological theory predicts that the ability of species to adapt to change decreases with increasing magnitude and lower predictability of environmental change (Fisher 1930). Such foundational truisms underscore how

Manuscript received 4 April 2018; revised 18 September 2018; accepted 3 December 2018. Corresponding Editor: Thomas J. Valone.

${ }^{10}$ E-mail: ajohnston@usgs.gov fundamentally challenging climate-based extreme events could be for species' persistence. Increasing occurrence and severity of extreme weather events are among the most-certain of predicted outcomes associated with contemporary climate change (IPCC 2014); however, little is known about how biotic responses to weather extremes vary across species, ecological context, and gradients of weather severity (Sergio et al. 2018). Weather extremes can reveal species vulnerability to climate change through exposure to environmental conditions that test 
physiological limits or through modification of essential resources (Moreno and Møller 2011, Wingfield 2013). Although many studies have related changes in species to long-term averages of temperature and precipitation, such metrics are likely proxies for the underlying mechanism of exposure to chronic- or extreme-weather events that affect populations and their distributions (MoránOrdóñez et al. 2018). Despite extensive evidence of change to biotas from recent climate change, few studies have identified the mechanistic relationships driving those changes (Cahill et al. 2012).

Snowpack reductions associated with climate change (Mote et al. 2005) are exacerbated by extremely warm weather (Mote et al. 2016) that could transform montane ecosystems by affecting water availability, vegetation, animal movement, phenology, and protective cover for subnivean biota (Penczykowski et al. 2017). Ultimately, these changes can reduce the amount, distribution, and connectivity of habitat for alpine species (Rehnus et al. 2018). Snowpack has already decreased significantly over the past century, and years of extremely low snowpack due to unusually warm temperatures, as seen recently in western North America, are expected to become more common (Marlier et al. 2017). Such snowpack anomalies could reveal the sensitivity of species to extreme weather and provide insight on species' adaptive capacity (Beever et al. 2017) to cope with climate change.

To understand how and why the distribution of a species changes, it is important to consider life history of the focal species and develop predictors that represent specific mechanisms that are hypothesized to have a clear pathway to influence species with those life-history characteristics. The American pika (Ochotona princeps) is a climate-sensitive species found in montane ecosystems of western North America and may be especially vulnerable to changes in snowpack because of their adaptations to cold environments (Morrison and Hik 2007, Yandow et al. 2015). Pikas are active year-round, rely on haypiles to overwinter, live beneath snow (Smith and Weston 1990), and are sensitive to both high heat (MacArthur and Wang 1973) and extreme cold (Wunder 1992, Beever et al. 2011). Hypothesized mechanisms for their sensitivity to snow drought include fatal exposure to extreme cold in the absence of snowpack (Smith et al. 2004). Altered phenology of principal forage species for pikas may also extend periods without green vegetation and lead to starvation (Morrison et al. 2009). Generic predictors of weather or climate are likely inadequate to discriminate among the mechanisms that drive population dynamics (Mathewson et al. 2017), particularly those mechanisms associated with snow drought.

We related relative abundances of pikas to weather and snowpack dynamics over an 8-yr period that included a year with record-low snowpack (Mote et al. 2016) in winter 2014-2015 (hereafter, winter 2015) to (1) quantify effects of low snowpack and (2) evaluate hypothesized mechanisms that could influence population dynamics of this species. We developed novel predictors for models that represented the interactive effects of temperature, precipitation, moisture, and snowpack on pika abundances. We hypothesized that pika abundances following the winter weather anomaly would be lower than previous years and that differences would be best explained by inter-annual variation in snowpack. We expected (1) that pika responses to extreme cold would depend on the presence of snowpack and (2) that atmospheric moisture, indexed by vapor pressure deficit (VPD), would mediate pikas' relationships to exposure to extreme heat and cold (Jeffress et al. 2013). Therefore, we developed predictors that represented (1) exposure to cold in the absence of snowpack and (2) the influence of VPD. Although heat exposure has explained range contractions for pikas at low latitudes, we expected that winter weather dynamics would explain more variation in pika abundances than summer conditions because of the abundant winter snowfall and mild summer temperatures typical of our study area.

\section{Methods}

\section{Study area}

The North Cascades National Park Service Complex (hereafter, the Park), which comprises North Cascades National Park, Ross Lake National Recreation Area, and Lake Chelan National Recreation Area, is in northcentral Washington, USA, and consists of roadless wilderness except for one road bisecting the Park (Fig. 1). Steep mountains with conifer forests dominate the Park, where elevations range from 100 to $2,800 \mathrm{~m}$. Annual precipitation in the Cascade Mountains ranges $50-500 \mathrm{~cm}$ based on proximity to mountain divides (Mote et al. 2003), and several vegetative life zones reflect wet, dry, or subalpine conditions. Weather station data from 2003 to 2017 at Thunder Basin (elevation $1,317 \mathrm{~m} ; 48.52^{\circ} \mathrm{N}, 120.98^{\circ} \mathrm{W}$; NRCS 2017) indicated that mean maximum temperatures ranged $17.6-23.6^{\circ} \mathrm{C}$ and accumulated precipitation ranged $4.1-49.0 \mathrm{~cm}$ during summer. Mean minimum ambient temperatures ranged $-7.3^{\circ} \mathrm{C}$ to $-3.4^{\circ} \mathrm{C}$ and accumulated precipitation ranged 33.8-89.4 cm during winter. Days of snow cover ranged 174-239 d, and the date of snow melt occurred between 13 May and 27 June. The weather anomaly in winter 2015 created the shortest duration of snowpack $(174 \mathrm{~d})$ and earliest date of melt-off (13 May) during this period. The second shortest duration of snowpack was 196 d, which melted off 21 May 2004. Pikas occupied talus throughout alpine and subalpine regions of the Park.

\section{Field methods}

We resurveyed sites of pika occurrence from previous studies in the Park to measure their relative abundance for our assessment of weather and snowpack dynamics. 


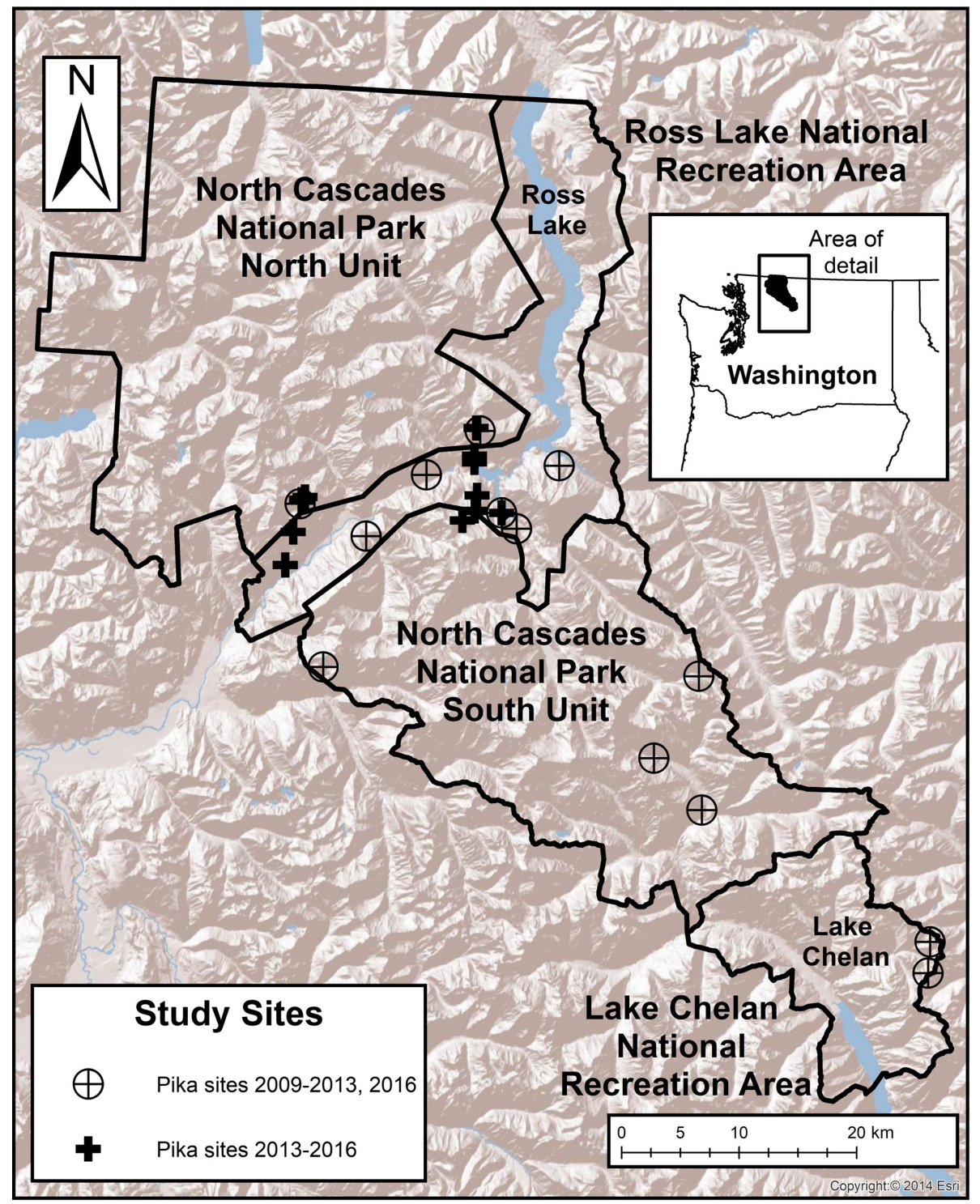

FIg. 1. Survey sites for American pikas (Ochotona princeps) in the North Cascades National Park Service Complex, Washington, USA, 2009-2016 (ESRI 2014).

In 2009, Bruggeman (2014) surveyed pikas at 30, 1-km² sites that were distributed within $3 \mathrm{~km}$ of roads or trails, following a stratified random design based on location relative to mountain-range divides and classes of low $(<914 \mathrm{~m})$, moderately low $(914-1,218 \mathrm{~m})$, middle (1,219-1,523 m), moderately high (1,524-1,827 m), and high $(\geq 1,828 \mathrm{~m})$ elevation. Pikas are talus obligates, and each site comprised one or more talus patches. In 2016, we surveyed a subset of 13 sites with 58 talus patches that was stratified by elevation and proximity to mountain divides. These sites had annual measures of relative abundances of pikas during 2009-2013, inclusive. We also surveyed pikas at another set of 11 sites, each of which comprised one talus patch that was surveyed from 2013 to 2015 . These 11 sites were distributed along three elevational transects (Thornton Lakes 490-1,700 m, Sourdough 465-1,650 m, Pyramid Peak 475-1,555 m) that were part of a study on pika genetics (Russello et al. 2015).

To ensure estimates of relative abundance were comparable across years, we adopted methods applied in previous surveys (Bruggeman 2014). To count pikas, surveyors walked parallel transects spaced $10 \mathrm{~m}$ apart and covering each talus patch within each site. We minimized differences in surveyor experience through rigorous, extensive training, although some surveyors had several seasons of experience, whereas others did not. In 2016, our highly experienced surveyor detected an average of $10.6 \mathrm{pikas} / \mathrm{d}$, whereas our three novice surveyors detected 10.1, 12.1, and 14.7 pikas/d. All 122 surveys 
from 2009 to 2016 occurred between 7 July and 24 October, with $8 \%, 60 \%, 30 \%$, and $2 \%$ of surveys performed in July, August, September, and October, respectively. Pika counts increased by 0.0048 pikas per day of year of the survey $\left(\chi_{1}^{2}=4.4, P=0.036,95 \%\right.$ confidence interval: 0.0003-0.0092), based on a mixed-effects model with a negative binomial distribution. This model estimated a survey-date bias of 0.4 pikas for the largest difference of $83 \mathrm{~d}$ in survey dates across years and within sites for this study. Reported detection probabilities for pikas have been consistently high across several regions (range 0.89-0.97; Beever et al. 2008, Rodhouse et al. 2010, Beever et al. 2011). As found in other studies, pikas in our sites were talus obligates, highly territorial, highly visible, vocal, and easily evident from conspicuous haypiles. Cumulatively, all these factors apparently led to high detection probabilities. We concentrated survey efforts during mid to late summer to minimize any seasonal biases in detectability. Although snow could limit access to some sites until mid-summer, correlation of survey dates with elevation was low $(r=0.21)$. Pika counts were based on the number of detections by sighting, vocalization, and active haypile presence (i.e., green vegetation present). For the 11 sites along elevation transects, we also included fresh scat as an indicator of current pika occupancy, following the protocol from previous years. Pika scat was distinctive and most commonly observed on rock surfaces, where vegetation was sparse $(<3 \%$ cover). The use of fresh scat as the sole indicator of pika presence was rare (i.e., only $13 \%$ of pika detections in 2016 across the 11 sites in which scat was part of the protocol) because fresh haypiles or individual pikas were usually detected (via sightings or calls) in association with fresh scat. To avoid double counting, we attributed multiple haypiles and fresh scat $<25 \mathrm{~m}$ apart to a single pika because their territories are exclusive and typically cover $<2,000 \mathrm{~m}^{2}$ (Smith and Ivins 1984). If a fresh haypile or scat occurred within $25 \mathrm{~m}$ of two other signs (fresh haypile or fresh scat), but those two signs were $>25 \mathrm{~m}$ apart, then we marked 2 pikas for the area. The distance of $25 \mathrm{~m}$ as a threshold was chosen because it is the approximate midpoint among all values of nearestneighbor distances reported in the literature (Smith and Weston 1990). We avoided double counting by noting and geo-referencing pika detections during surveys.

\section{Weather and snowpack data}

We characterized weather and snowpack dynamics at each site with metrics of temperature, VPD, precipitation, and snow water equivalents (SWE) from gridded climate surfaces for 2003-2016 (Appendix S1: Table S1). For most predictors, we used daily metrics of temperature extremes, VPD extremes, and precipitation from PRISM (Parameter-elevation Relationships on Independent Slopes Model) version AN81d at 800-m spatial resolution (Daly et al. 2008). We obtained daily measures of SWE at 1-km resolution from Daymet (Thornton et al. 2017) to characterize snowpack. These gridded climate data are available as continuous rasters of daily values for weather cover the coterminous United States (PRISM) or most of North America (Daymet). Values in rasters are calculated based on weather station data, physiography, and many other factors. The spatial resolution of the weather data was the finest available for this region. Although individual pikas are influenced by microclimates that occur at finer spatial scales, the gridded climate data were useful to address our questions because sites were widely distributed across gradients of temperature, precipitation, moisture, and snowpack.

We selected predictors for an a priori model set to represent mechanisms tested in earlier studies and previously untested mechanisms that we hypothesized might be important based on decades of pika research (Fig. 2). Most predictors represented mechanisms of stress from extreme temperatures or water stress that were inspired by results of previous studies (heat stress [Beever et al. 2011, 2016, Stewart et al. 2015]; cold stress [Beever et al. 2011]; and water stress [Beever et al. 2013, 2016, Millar et al. 2018]) and the concern over cold exposure in the absence of snowpack (Morrison and Hik 2007, 2008), a mechanism that has received little attention empirically. Our predictors for summer weather expressed growingseason precipitation, VPD, and exposure to chronic (i.e., mean daily maximum temperatures for July-August) or acute (i.e., number of days $>25^{\circ} \mathrm{C}$ ) heat. Minimum values of VPD typically coincided with the minimum temperature and represented chronic dryness. Sites that achieved zero deficit experienced condensation, which can have

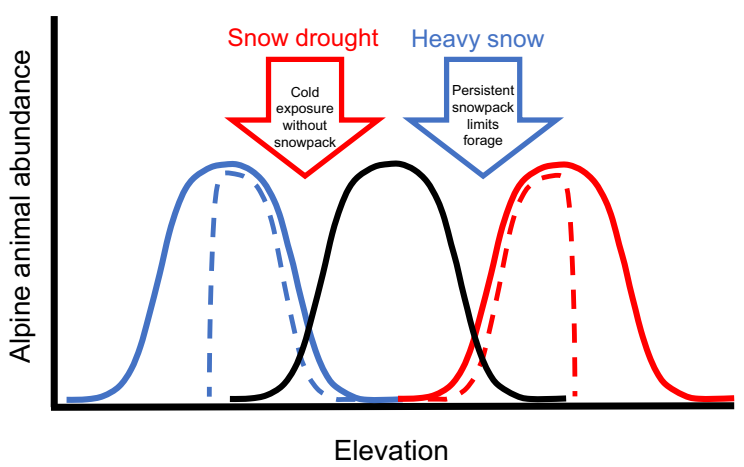

FIG. 2. Suitable habitat for a mountain-dwelling species can shift across years based on snowpack dynamics. Hypothesized distributions of alpine animals in years of below-average (red line) and above-average (blue line) snowpack are shown relative to the distribution in a normal snow year (black line) in an idealized montane ecosystem. In years of above-average snowpack, persistent snowpack that limits forage availability at high elevations can occur at lower elevations (blue arrow) and shift the population distribution downslope. During snow drought, cold exposure in the absence of snowpack can stress animals (red arrow) and shift the population distribution upslope. Where shifts to high or low elevations are biophysically limited by habitat (e.g., soil suitability, forage availability, mountaintop, competitors), animal abundances may shift to a truncated distribution (dashed lines). 
important implications for biota through water availability (Breshears et al. 2013). We used maximum values of VPD to represent the severity of dryness at a site, which might index acute stress from dehydration. Minimum and maximum VPD in summer had low correlation $(r=0.03)$, indicating that these metrics represented distinct aspects of moisture.

For winter weather, our predictors expressed snowpack duration, VPD, and exposure to acute (i.e., number of days with temperature $<-10^{\circ} \mathrm{C}$ ) or chronic (i.e., mean minimum temperature from November to February) cold either throughout the year, or expressly at times without snowpack (acute, minimum daily temperature; chronic, number of days with temperature $<0^{\circ} \mathrm{C}$; Appendix S1: Table S1). We defined snowpack presence as $\mathrm{SWE} \geq 30 \mathrm{~mm}$ because snow depths $>20 \mathrm{~cm}$ provide insulation for pikas (Danby and Hik 2007) and our threshold corresponds to snow depth of approximately $10 \mathrm{~cm}$ for snowpack of moderate density $\left(300 \mathrm{~kg} / \mathrm{m}^{3}\right)$, typical in the North Cascades (Mizukami and Perica 2008). We expected that VPD minimums and maximums would represent exposure to chronic and acute dryness in winter, respectively. In addition, cold exposure could be accentuated at sites with low minimum VPD in winter (McArthur 1991). Correlation between minimum and maximum VPD during winter was also low $(r=0.36)$. All predictors were standardized to a normal distribution with a mean of 0 and standard deviation of 1 for the analysis.

\section{Analytical methods}

We related relative abundance of pikas to measures of weather and snowpack dynamics with a priori regression models that represented specific, hypothesized mechanisms of influence on the distribution of this species (Appendix S1: Table S2). We used generalized linear models with mixed effects in $\mathrm{R}$ package lme4 (Bates et al. 2015, R Core Team 2017) to analyze counts of pikas from each year of the study. We used a negative binomial distribution for pika counts to account for overdispersion. Each model had the study site as a random effect to facilitate the analyses of repeated measures, which examined changes in abundance within each site over time and accounted for differences in habitat (e.g., proximity to water, talus amount) among sites. We related counts of pikas from each year to the summer conditions during the survey or to the winter conditions that immediately preceded the pika surveys for that year. In addition, we evaluated models with predictors that represented a 1-yr lag effect by relating counts to weather and snowpack conditions of the previous year. Analyses assumed constant detectability for pikas over the study period because of consistently high probabilities reported across several regions (Beever et al. 2011).

We tested whether the relative abundance of pikas changed after winter 2015 with the interaction between elevation and the time of survey, defined as before or after winter 2015. Snowpack duration was imperfectly correlated with elevation due to slope, aspect, wind, and other factors that influence snow deposition (Kirchner et al. 2014), so we tested both types of interactions to determine whether measures of the snowpack anomaly explained more variation in relative abundance of pikas than elevation. For these tests and others on the significance of predictors in mixed-effects models, we used Type II Wald chi-square tests in the R car package (Fox and Weisberg 2011).

Models in the a priori sets represented either summer or winter conditions with three or fewer predictors (Appendix S1: Table S2). We excluded combinations of highly correlated predictors $(r \geq 0.75)$ within models. All univariate models were candidates. No multivariate models included more than one predictor of heat or cold exposure because of correlations among temperaturebased predictors. Exceptions were the combination of cold exposure predictors with those that expressed cold exposure without snowpack. Several models tested interactions between VPD and exposure to temperature extremes or snowpack duration. We also tested interactions between growing-season precipitation and heat exposure. Model selection and inference followed an information-theoretic approach, where support for hypotheses was based on Akaike information criteria for small sample sizes $\left(\mathrm{AIC}_{\mathrm{c}}\right.$ ) and Akaike weights (Burnham and Anderson 2002). We also assessed model fit with marginal and conditional coefficients of determination $\left(R^{2}\right)$ following an $\mathrm{R}$ script for negative binomial models from Nakagawa et al. (2017). The marginal $R^{2}$ measures the variation explained by only the fixed effects, whereas the conditional $R^{2}$ measures variation explained by fixed and random effects combined.

\section{RESULTS}

We detected 3,105 pikas from 2009 through 2016 (Appendix S1: Table S3). Changes in relative abundance of pikas after the low-snow year of 2015 depended on elevation $\left(\chi_{1}^{2}=10.9, P<0.001\right)$ : relative abundances generally decreased at low-elevation sites but increased at sites above 1,400 m (Fig. 3A, C). Elevation was correlated with many of our climate predictors including snowpack duration in $2015(r=0.87)$, and elevation alone explained nearly as much variation in relative abundance of pikas as did the snowpack duration of 2015 (Fig. 3B, D; $\chi_{1}^{2}=13.6, P=<0.001, \Delta \mathrm{AIC}_{\mathrm{c}}=1.27$ ). Patterns in relative abundance of pikas suggested that the shift in relative abundance occurred after the summer of 2015, rather than immediately after the winter of 2014-2015. This is evidenced by the strong support garnered by models with 1-yr lag effects from snowpack and weather. In addition, pika abundances in summer 2015, immediately following the snow drought, were similar to 2014 abundances at the 11 sites with surveys from 2013 to 2016. The pattern of lower abundances at low elevations and higher abundances at high elevations, 
relative to years prior to 2016, was consistent with the pattern we observed at the other 13 sites that were surveyed 2009 to 2013 and 2016.

The top-ranked model included the interaction between snowpack duration and winter VPD minimum with a 1-yr lag effect (Table 1). The interaction indicated that relative abundance of pikas increased with snowpack duration and winter-time VPD, but pikas decreased with increasing VPD in areas with little or no snowpack (Fig. 4). The model explained $85 \%$ of the conditional variation (i.e., fixed and random effects) and
$10 \%$ of the marginal variation (i.e., fixed effects) in relative abundance of pikas. The top-ranked model had strong support (Akaike weight $=0.65$ ), and the secondbest model was not equally plausible $\left(\Delta \mathrm{AIC}_{\mathrm{c}}=2.4\right)$. Relative abundance of pikas was influenced more strongly by winter, rather than summer, weather dynamics (Tables 1, 2); models for pikas with predictors of winter weather or snowpack dynamics had a cumulative Akaike weight of 0.90 . The best model based on any aspect of summer weather was not competitive $\left(\Delta \mathrm{AIC}_{\mathrm{c}}=6.3\right)$ and had an Akaike weight $=0.03$.
A

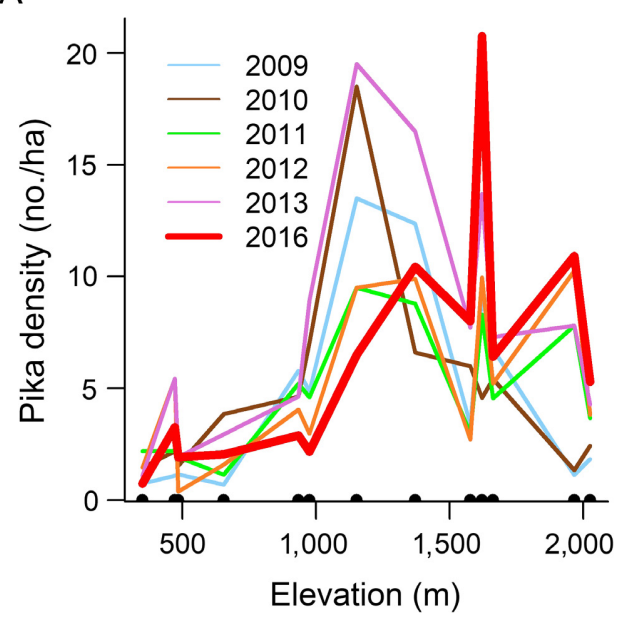

C

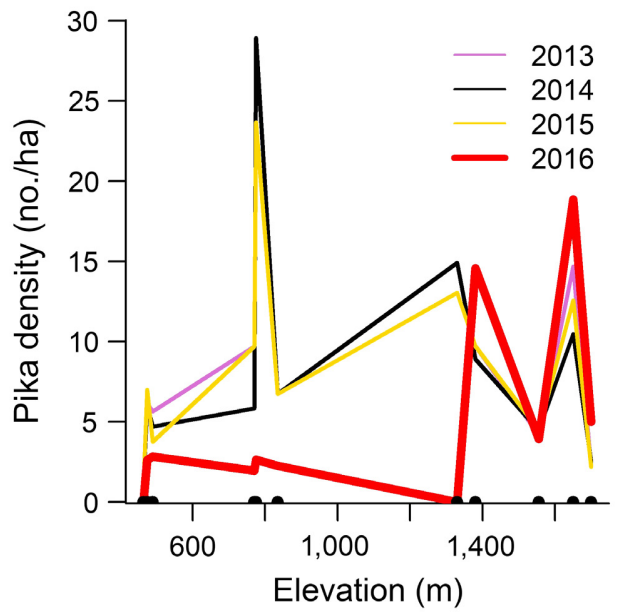

B

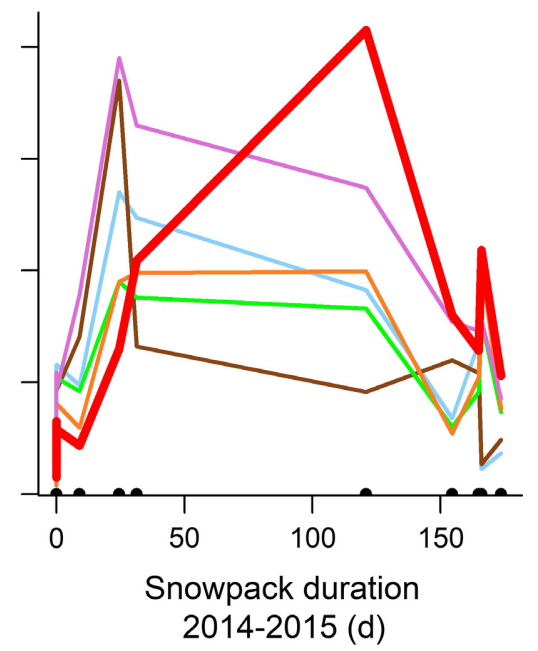

D

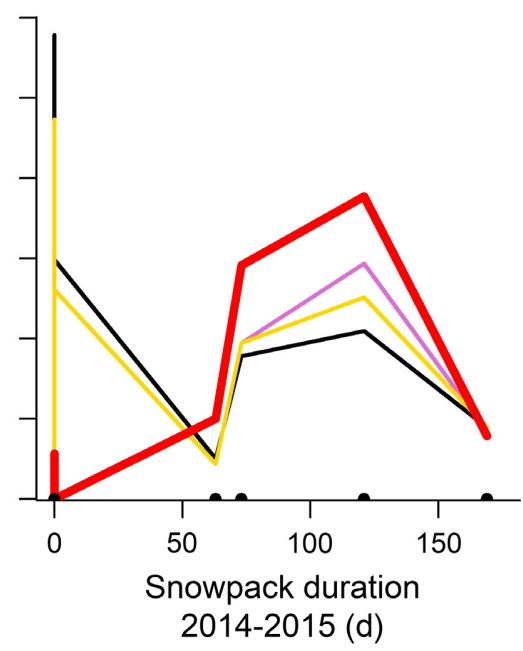

FIG. 3. Relative densities of American pikas with elevation and 2014-2015 snowpack duration at North Cascades National Park, Washington, USA. (A, B) Pika surveys occurred at 13 sites during 2009-2013 and 2016 and (C, D) at a different set of 11 sites during 2013-2016. We calculated relative density of pikas for each site in each year as the number of pikas counted divided by the area of talus within sites and plotted these values to depict patterns in abundance that were detected in the analyses of repeated measures. We ordered the sites from shortest to longest duration of snowpack based on the year of the drought to illustrate any patterns in abundance with increasing duration of snowpack when snowpack was at a record low. For pikas, the response of decreasing abundance switched to increasing abundance around $50 \mathrm{~d}$ of snowpack duration, or $1,400 \mathrm{~m}$ of elevation. Black points on the $x$ axes represent the values of elevation or snowpack duration for sites. These points overlap at several sites that had no snow during winter 2014-2015. 
TABle 1. Differences in Akaike's information criterion for small sample sizes $\left(\Delta \mathrm{AIC} C_{\mathrm{c}}\right)$, model weights $\left(w_{\mathrm{i}}\right)$, and variation explained ( $R_{\mathrm{c}}^{2}$, conditional; $R_{\mathrm{m}}^{2}$, marginal) for the three topranked models plus the null model in analyses for relative abundance of American pikas in North Cascades National Park, Washington, USA, 2009-2016.

\begin{tabular}{lcccc}
\hline \hline Model & $\Delta \mathrm{AIC}_{\mathrm{c}}$ & $w_{\mathrm{i}}$ & $R_{\mathrm{c}}^{2}$ & $R_{\mathrm{m}}^{2}$ \\
\hline Winter VPDmin $\times$ & 0 & 0.651 & 0.85 & 0.10 \\
$\quad$ Snowpack duration & & & & \\
Winter VPDmin $\times$ Chronic cold & 2.42 & 0.194 & 0.85 & 0.09 \\
Summer VPDmin + & 6.30 & 0.028 & 0.81 & 0.19 \\
$\quad$ Acute heat + GSP & 14.1 & 0.001 & 0.83 & 0 \\
Null & & & \\
\hline
\end{tabular}

Notes: VPDmin, minimum vapor pressure deficit; GSP, growing-season precipitation. All models in this table had site as a random factor and predictors that represented 1-yr lag effects. Models with interactions $(x)$ included main effects for each interacting predictor.

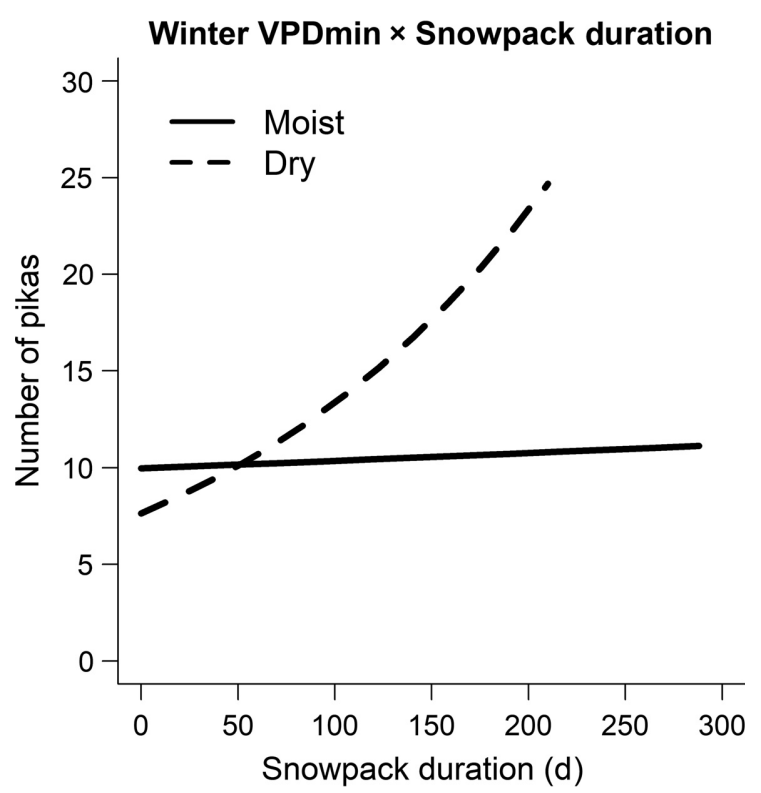

FIG. 4. Predicted values from the best model for relative abundance of American pikas, as explained by the interaction of winter vapor pressure deficit (VPD) minimum and snowpack duration in the analysis of relative abundances for pikas in North Cascades National Park, Washington, USA, 2009-2016. Relative abundances of pikas increased with VPD and snowpack duration, except in areas with little or no snowpack. Predictions are based on mean intercepts for the random sites. Moist and dry prediction lines are based on the 10th (moist) and 90th (dry) percentile values of winter VPD minimum observed within each data set. Predictions cover the approximate range of values for the combinations of VPD and snowpack duration observed in the data set.

\section{Discussion}

The importance of VPD and its interaction with snowpack duration was a notable result that revealed (1) context dependency in pika responses to snow drought and (2) potential to advance mechanistic understanding
TABLE 2. Coefficient signs of predictors and sums $(w+)$ and means $\left(\bar{w}_{i}\right)$ of Akaike weights of models with each predictor in analyses of relative abundances of American pikas in North Cascades National Park, Washington, USA, 2009-2016.

\begin{tabular}{|c|c|c|c|c|}
\hline Predictor & Season & $w+\dagger$ & $\bar{w}_{i}$ & Sign \\
\hline Snowpack duration (d) & winter & 0.666 & 0.111 & + \\
\hline $\begin{array}{l}\text { Minimum vapor } \\
\text { pressure deficit }(\mathrm{kPa})\end{array}$ & winter & 0.865 & 0.079 & + \\
\hline Chronic cold $\left({ }^{\circ} \mathrm{C}\right)$ & winter & 0.212 & 0.030 & - \\
\hline $\begin{array}{l}\text { Minimum vapor } \\
\text { pressure deficit }(\mathrm{kPa})\end{array}$ & summer & 0.056 & 0.011 & + \\
\hline Acute heat (d) & summer & 0.040 & 0.008 & - \\
\hline $\begin{array}{l}\text { Growing-season } \\
\text { precipitation }(\mathrm{mm})\end{array}$ & summer & 0.056 & 0.007 & + \\
\hline Chronic heat $\left({ }^{\circ} \mathrm{C}\right)$ & summer & 0.023 & 0.005 & - \\
\hline $\begin{array}{l}\text { Maximum vapor } \\
\text { pressure deficit }(\mathrm{kPa})\end{array}$ & winter & 0.014 & 0.001 & + \\
\hline Acute cold $(\mathrm{d})$ & winter & 0.005 & $0 \S$ & - \\
\hline $\begin{array}{l}\text { Acute cold without } \\
\text { snowpack }\left({ }^{\circ} \mathrm{C}\right)\end{array}$ & winter & 0.003 & 0 & + \\
\hline $\begin{array}{l}\text { Chronic cold without } \\
\text { snowpack (d) }\end{array}$ & winter & 0.002 & 0 & - \\
\hline $\begin{array}{l}\text { Maximum vapor } \\
\text { pressure deficit }(\mathrm{kPa})\end{array}$ & summer & 0 & 0 & - \\
\hline
\end{tabular}

† Signs and Akaike weights are from models with 1-yr lags because models without the time lag did not have weights $>$ 0.001 .

\$ Coefficient signs were consistent across all models. Signs represent results from models with main effects only.

$\S$ Values $<0.001$ are reported as 0 .

of animal distributions (Riddell et al. 2017) with new gridded climate data for atmospheric moisture (Daly et al. 2015). To our knowledge, our top model is unprecedented in its application of VPD as a predictor of either animal population dynamics or endotherm distribution. Moisture is an important aspect of climate that influences water stress on biota and their habitat (Monteith 1965); however, few studies have used any metric of moisture to evaluate animal distributions (Beever et al. 2017). Water vapor exerts pressure on liquid water and condenses to liquid when actual vapor exceeds the level of saturation (Stull 2011). The Clausius-Clapeyron equation describes how the capacity of air to hold water vapor increases exponentially with temperature, which influences rates of evaporation and condensation. Vapor pressure deficit is the absolute difference between actual vapor pressure and the pressure at saturation for a given temperature and represents the drying effect of air on biota. As an index of moisture, VPD is distinct from relative humidity in its expression of water stress independent of temperature (Anderson 1936) and, consequently, VPD has a strong relationship with evapotranspiration (Zhang et al. 2014), which can index important ecological information for species.

Atmospheric moisture can affect species directly through physiological stress from dehydration or effects on thermoregulation. Many animals, including birds, lizards, and amphibians, have low skin resistance to 
water loss (Lillywhite 2006), which constrains their activities and distribution. These relationships can be explained with VPD to improve mechanistic models of species distributions (Riddell et al. 2017). The insulative properties of fur are reduced by accumulated moisture from rain or condensation, resulting in significant heat loss for mammals (McArthur 1991, McArthur and Ousey 1996). Furthermore, increases in visitation of water sources by some mammals have been explained by increases in VPD, illustrating behavioral responses to changes in atmospheric moisture (Harris et al. 2015). The relationship of VPD to plant function (e.g., stomatal closure at high VPD) is well understood (Oren et al. 1999), and recent studies have reported widespread changes to vegetation explained by VPD (Williams et al. 2013, Konings et al. 2017). Because vegetation is often fundamental to wildlife habitat, VPD also can influence animals indirectly through changes in cover or forage species. For subnivean wildlife, the insulative capacity of snowpack and the subnivium can be reduced by increased density of snow from excessive moisture, rain on snow, or melt and refreeze events (Pauli et al. 2013). Despite the pervasive influence of moisture on biota and expected increases in VPD from contemporary climate change (Ficklin and Novick 2017), little is known about effects of VPD on animal distributions.

\section{Direct vs. indirect mechanisms}

Our top model indicated that pikas were directly affected by winter weather and snowpack, contrary to more common mechanisms of biotic interactions that arise from climate change (Ockendon et al. 2014). However, we suggest that the influence of direct and indirect effects of weather was context-dependent and not mutually exclusive. Despite the importance of snowpack duration, pikas did not exhibit high mortality from cold exposure during the winter with record-low snowpack, and predictors that represented cold exposure without snowpack explained little variation in their relative abundances (Appendix S2: Table S1). Rather, pikas exhibited 1 -yr lags in their response to weather and snowpack, suggestive of poor reproduction or survival after winters with little snowpack at low elevations. At our sites, the decrease in pika abundance at low elevations simultaneous with increases at higher elevations one year after the snow drought suggests that conditions were stressful for pikas at low elevations during winter 2015, while pikas at high elevations had sufficient snow cover for insulation and benefitted from increased forage availability due to the earlier snowmelt. At low elevations, pikas may have resorbed fetuses (Millar 1974) in response to sublethal stress that occurred during the snow drought. Cold exposure in the absence of snowpack was more severe at low vs. high elevations (Appendix S1: Text S1, Fig. S1) and may have been a factor for pikas at mid-elevation sites $(1,000-1,400 \mathrm{~m})$, where snowpack duration ranged $0-71 \mathrm{~d}$ during the drought. Below $1,000 \mathrm{~m}$, the lack of snowpack during the snow drought was not unusual for pikas based on our metric of snowpack duration. Post hoc analyses of mid-elevation sites $(n=4)$ indicated that pikas were negatively affected by acute $\left(\chi_{1}^{2}=5.9, P=0.015\right)$ and chronic cold stress $\left(\chi_{1}^{2}=3.8\right.$, $P=0.066)$ in the absence of snowpack, whereas there was no evidence of these effects at lower ( $n=12$ sites) or higher ( $n=8$ sites) elevations $(P \geq 0.276)$. This suggests that cold stress due to lack of insulation from snowpack is influential within a narrow band along the elevation gradient, where temperatures can be stressfully low, and snowpack is sometimes inadequate to provide insulation. However, the severity of cold stress without snowpack at mid-elevation sites during the snow drought was not extreme in our time series (Appendix S1: Text S1, Table S5, Fig. S1). The effects of increasing VPD on pikas were negative at low $\left(\chi_{1}^{2}=5.2, P=0.023\right)$ and mid $\left(\chi_{1}^{2}=0.5, P=0.49\right)$ elevations, but positive at high elevations $\left(\chi_{1}^{2}=9.6, P=0.002\right)$. At low elevations, unusually high VPD during the snow drought may have desiccated forage species and prompted malnourished pikas to forgo reproduction. In the Pacific Northwest, pikas at low elevations rely on atypical forage species such as moss (Varner and Dearing 2014a) that are highly sensitive to VPD (Charron and Quatrano 2009). At high elevations, snowpack was likely adequate to provide insulation during the coldest times of the snow drought and protected vegetation from high VPD because snowpack durations ranged 63-174 d. The interaction between VPD and snowpack duration in our top model captured this context dependency by modeling loss of pikas at sites with little or no snowpack (i.e., $<1,400 \mathrm{~m}$ elevation) during the snow drought coincident to increases in pikas at high elevations.

If timing of earlier melt-off improves productivity of forage species or lengthens the growing season at higher elevations, pikas may consume and collect enough food to increase fecundity or survival over the following winter. Pikas are diet generalists that consume forbs, graminoids, and foliage of shrubs and trees (Dearing 1996). Experimental snow removals alter plant phenology and increase exposure to frost damage (Sherwood et al. 2017), which can change composition and abundance of vegetation. Bhattacharyya and Ray (2015) observed significant changes in haypile composition that coincided with a trend in earlier melt-off in the southern Rockies, where amounts of vegetation high in secondary metabolites decreased as snow melt occurred earlier. These studies suggest vegetation relevant to pikas has been changing with climate, but we know little about the interactive effects of snow and vegetation dynamics on pikas.

Our models for biotic effects (e.g., growing-season precipitation) did not explicitly model effects of vegetative phenology and productivity on pika abundance. Therefore, we conducted a post hoc analysis of pika counts with metrics of vegetative phenology and productivity from time series of the normalized difference 
vegetation index (NDVI) in imagery from the Moderate Resolution Imaging Spectroradiometer (MODIS; Gao et al. 2006; Appendix S2). Although models of vegetative phenology and productivity explained significant variation in the relative abundances of pikas, they were not competitive with our top a priori models. Our observation of higher pika abundances above $1,400 \mathrm{~m}$ in 2016, compared to pre-drought years, was consistent with our hypotheses that abundances would increase following years of high vegetative productivity (Appendix S2: Fig. S2). Results of the vegetation analysis suggest that the snow drought led to greater forage availability at high elevations based on cumulative NDVI, which likely benefitted pikas in those areas. Therefore, we suggest that pikas were affected by snow drought through changes in forage availability at low and high elevations, but cold exposure in the absence of snowpack was influential at mid elevations. Further, we suggest that our results were related to changes in pika fecundity, rather than overwinter survival a year after the drought, because our vegetation metrics did not suggest any shortage of forage associated with changes in phenology following the snow drought. Although we could not consider alternative mechanisms of disease or predators, the good explanatory power of our models and the rapid, simultaneous decrease and increase in pikas across the snow gradient after the drought suggest the patterns in pika abundances that we observed were predominantly related to weather.

Snowpack is probably less important in regions or in years with mild winters when there is little exposure to extreme cold in the absence of snowpack. Also, snowpack may be more important in places where water is more of a limiting factor. However, more research is needed to fully understand any regional variation in the importance of snowpack to pikas. Other studies have indicated that snowpack is important to pikas for insulation from cold exposure in the Great Basin (Beever et al. 2010), Wyoming (Yandow et al. 2015) and across the western United States (Schwalm et al. 2016). Lag effects of early snowmelt increased survival rates, but not reproduction, of collared pikas (O. collaris) in Canada (Morrison and Hik 2007). In Wyoming, reproduction of American pikas was highest at sites with relatively early snowmelt (Kreuzer and Huntly 2003). Pikas in some of these regions may have benefitted from earlier availability of forage during spring. In contrast, Smith and Millar (2018) did not detect any effects of the 2014-2015 snow drought based on occupancy of American pikas in California. The variable results across these studies suggest context dependency in pika responses to snowpack across regions, but uncertainty remains due to inconsistencies among studies in the response (abundance vs. occupancy) and the range of conditions that were observed. For example, Smith and Millar (2018) did not formally analyze pika abundances or exposure to extreme temperatures at their sites. All weather stations reported in that study had $\mathrm{SWE} \geq 3.8 \mathrm{~cm}$ on 1 April
2015, whereas $50 \%$ of our sites did not have any snowpack during winter 2015. It is unclear whether pikas from that study were exposed to similar conditions to our study or others. Nearly all our sites were occupied by pikas throughout our study, such that we would not have detected the strong influence of snowpack or any other effect of weather on pikas in an analysis limited to occupancy. This result underscores the importance of abundance, rather than occupancy, as an early-warning indicator of change in pika populations (Beever et al. 2013).

Coping strategies or adaptations to snow drought by pikas were not apparent in our study. Like many species with low vagility, individual pikas may be unable to move to areas with adequate snowpack during extreme snow drought because travel to distant microrefugia may be energetically costly. If exposure to extreme cold is a factor, pikas may seek shelter beneath snow drifts or within deep talus, where temperatures are relatively stable (Millar et al. 2014). Movement to higher elevations might allow pikas to find areas with sufficient snowpack, unless movement is limited by a mountaintop, vegetation distribution, or a long distance to a suitable talus patch. Pikas use metabolism of brown fat in non-shivering thermogenesis, but when the fat is exhausted, pikas can succumb to hypothermia during stressful winter conditions (Wunder 1992). Pikas can cope with water stress and malnourishment via concentrating urine and coprophagy (Smith and Weston 1990), but the importance of VPD to pikas can be related to thermoregulation, rather than water stress or malnourishment. If traditional forage is limited under snow drought, pikas may adapt through dietary shifts to alternative foods like moss (Varner and Dearing 2014a) that can be abundant in areas that receive little snow.

\section{Winter weather and snowpack matter}

Weather and climatic factors that govern population dynamics of species likely vary across geographic ranges of species, dependent upon on where local climate falls within a species' bioclimatic niche (Jeffress et al. 2013). Although pikas are sensitive to summer heat at lower latitudes (Beever et al. 2016), winter weather dynamics were resoundingly more important in the Park. In the Pacific Northwest, pikas occur at extraordinarily low elevations because of maritime effects and climate refugia that minimize heat exposure (Varner and Dearing 2014b). Persistent snowpack probably limits forage availability for pikas at high elevations in the Park (Morrison and Hik 2007) because this region receives the highest annual snowfall in the world ( $29 \mathrm{~m}$; Cerveny et al. 2007). The geographic range for pikas covers extensive regions at lower latitudes in warmer, drier portions of North America, where pikas respond positively to moisture (Beever et al. 2016, Millar et al. 2018) for reasons that may be related to dehydration or forage quality. Contrary to the common finding that range retractions 
associated with climate change occur primarily at the warm edges of species' ranges (Wiens 2016), our results indicate that species losses from climate change can occur away from warm edges of geographic ranges, including cold regions with substantial snowpack. Few researchers have evaluated effects of climate change on relatively cold portions of species ranges, and the consequences of snow drought for subnivean wildlife have received little attention (Penczykowski et al. 2017).

\section{Conclusions}

Predicted increases in the frequency of extreme weather events such as snow drought will continue to test long-held theory that species' adaptability depends on the magnitude and predictability of environmental change (Fisher 1930). Pikas were sensitive to snow drought, and recovery of abundances at low elevations may be at risk with increased drought frequency and higher VPD. Further declines in snowpack and moisture from climate change will likely be sources of significant changes in montane ecosystems over the next century. Our results demonstrate the nuanced and context-dependent responses of pikas to weather and snowpack dynamics that likely occur in other species. General climate predictors commonly used in species distribution models can be inadequate to capture the interactive effects of temperature, precipitation, moisture, and snowpack that influence animals. New gridded climate metrics for VPD (Daly et al. 2015) describe an important aspect of climate that is distinct from temperature and precipitation and will likely advance understanding of distributions for many species because of the pervasive influence of moisture on the physiology and habitat of biota. Extreme weather can change animal abundances quickly, especially when limits of physiological tolerance are reached, or biotic interactions become unfavorable. Mechanistic and long-term demographic studies are needed to improve understanding of biotic responses to increasingly unstable environments associated with climate change and identify the limits of species' persistence.

\section{ACKNOWLEDGMENTS}

We thank our many field assistants and volunteers. R. Tressler, Seattle City Light Wildlife Research Program, and R. Rocheforte, National Park Service, fostered research collaborations. D. Inouye, A. Smith, C. Millar, R. McCaffery and two anonymous reviewers provided helpful comments on the manuscript. This research was funded by the Seattle City Light Wildlife Research Program with support from the U.S. Geological Survey and National Park Service. Any use of trade, firm, or product names is for descriptive purposes only and does not imply endorsement by the U.S. Government.

\section{Literature Cited}

Anderson, D. B. 1936. Relative humidity or vapor pressure deficit. Ecology 17:277-282.
Bates, D., M. Mächler, B. M. Bolker, and S. C. Walker. 2015. Fitting linear mixed-effects models using lme4. Journal of Statistical Software 67:1-48.

Beever, E. A., S. Z. Dobrowski, J. Long, A. R. Mynsberge, and N. B. Piekielek. 2013. Understanding relationships among abundance, extirpation, and climate at ecoregional scales. Ecology 94:1563-1571.

Beever, E. A., L. E. Hall, J. Varner, A. E. Loosen, J. B. Dunham, M. K. Gahl, F. A. Smith, and J. J. Lawler. 2017. Behavioral flexibility as a mechanism for coping with climate change. Frontiers in Ecology and the Environment 15:299-308.

Beever, E. A., C. Ray, P. W. Mote, and J. L. Wilkening. 2010. Testing alternative models of climate-mediated extirpations. Ecological Applications 20:164-178.

Beever, E. A., C. Ray, J. L. Wilkening, P. F. Brussard, and P. W. Mote. 2011. Contemporary climate change alters the pace and drivers of extinction. Global Change Biology 17:2054 2070.

Beever, E. A., J. L. Wilkening, D. E. McIvor, S. S. Weber, and P. E. Brussard. 2008. American pikas (Ochotona princeps) in northwestern Nevada: a newly discovered population at a lowelevation site. Western North American Naturalist 68:8-14.

Beever, E. A., et al. 2016. Pika (Ochotona princeps) losses from two isolated regions reflect temperature and water balance, but reflect habitat area in a mainland region. Journal of Mammalogy 97:1495-1511.

Bhattacharyya, S., and C. Ray. 2015. Of plants and pikas: evidence for a climate-mediated decline in forage and cache quality. Plant Ecology \& Diversity 8:781-794.

Breshears, D. D., H. D. Adams, D. Eamus, N. G. McDowell, D. J. Law, R. E. Will, A. P. Williams, and C. B. Zou. 2013. The critical amplifying role of increasing atmospheric moisture demand on tree mortality and associated regional die-off. Frontiers in Plant Science 4:266.

Bruggeman, J. E. 2014. Abiotic and biotic factors affecting American pika populations in the North Cascades National Park Service Complex during 2009 through 2013. Final Report. Seattle City Light Wildlife Research Program, Seattle, Washington, USA.

Burnham, K. P., and D. R. Anderson. 2002. Model selection and multimodel inference: a practical information-theoretic approach. Springer-Verlag, New York, New York, USA.

Cahill, A. E., et al. 2012. How does climate change cause extinction? Proceedings of the Royal Society B 280:20121890.

Cerveny, R. S., J. Lawrimore, R. Edwards, and C. Landsea. 2007. Extreme weather records: compilation, adjudication, and publication. Bulletin of the American Meteorological Society 88:853-860.

Charron, A. J., and R. S. Quatrano. 2009. Between a rock and a dry place: the water-stressed moss. Molecular Plant 2:478486.

Daly, C., M. Halbleib, J. I. Smith, W. P. Gibson, M. K. Doggett, G. H. Taylor, J. Curtis, and P. P. Pasteris. 2008. Physiographically sensitive mapping of climatological temperature and precipitation across the conterminous United States. International Journal of Climatology 28:2031-2064.

Daly, C., J. I. Smith, and K. V. Olson. 2015. Mapping atmospheric moisture climatologies across the conterminous United States. PLoS ONE 10:e0141140.

Danby, R. K., and D. S. Hik. 2007. Responses of white spruce (Picea glauca) to experimental warming at a subarctic alpine treeline. Global Change Biology 13:437-451.

Dearing, M. D. 1996. Disparate determinants of summer and winter diet selection of a generalist herbivore, Ochotona princeps. Oecologia 108:467-478.

ESRI. 2014. World shaded relief [basemap]. http://goto.arcgison line.com/maps/World_Shaded_Relief 
Ficklin, D. L., and K. A. Novick. 2017. Historic and projected changes in vapor pressure deficit suggest a continental-scale drying of the United States atmosphere. Journal of Geophysical Research: Atmospheres 122:2061-2079.

Fisher, R. A. 1930. The genetical theory of natural selection. Oxford University Press, Oxford, UK.

Fox, J., and S. Weisberg. 2011. An R companion to applied regression. Second edition. Sage, Thousand Oaks, California, USA.

Gao, F., J. Masek, M. Schwaller, and F. Hall. 2006. On the blending of the Landsat and MODIS surface reflectance: predicting daily Landsat surface reflectance. IEEE Transactions on Geoscience and Remote Sensing 44:2207-2218.

Harris, G., J. G. Sanderson, J. Erz, S. E. Lehnen, and M. J. Butler. 2015. Weather and prey predict mammals' visitation to water. PLoS ONE 10:e141355.

IPCC. 2014. Climate change 2014: synthesis report. In Core Writing Team, R. K. Pachauri, and L. A. Meyer, editors. Contribution of Working Groups I, II and III to the Fifth Assessment Report of the Intergovernmental Panel on Climate Change. IPCC, Geneva, Switzerland, $151 \mathrm{pp}$.

Jeffress, M. R., T. J. Rodhouse, C. Ray, S. Wolff, and C. W. Epps. 2013. The idiosyncrasies of place: geographic variation in the climate-distribution relationships of the American pika. Ecological Applications 23:864-878.

Kirchner, P. B., R. C. Bales, N. P. Molotch, J. Flanagan, and Q. Guo. 2014. LiDAR measurement of seasonal snow accumulation along an elevation gradient in the southern Sierra Nevada, California. Hydrology and Earth System Science 18:4261-4275.

Konings, A. G., A. P. Williams, and P. Gentine. 2017. Sensitivity of grassland productivity to aridity controlled by stomatal and xylem regulation. Nature Geoscience 10:284-288.

Kreuzer, M. P., and N. J. Huntly. 2003. Habitat-specific demography: evidence for source-sink population structure in a mammal, the pika. Oecologia 134:343-349.

Lillywhite, H. B. 2006. Water relations of tetrapod integument. Journal of Experimental Biology 209:202-226.

MacArthur, R. A., and L. C. H. Wang. 1973. Physiology of thermoregulation in the pika, Ochotona princeps. Canadian Journal of Zoology 51:11-16.

Marlier, M. E., M. Xiao, R. Engel, B. Livneh, J. T. Abatzoglou, and D. P. Lettenmaier. 2017. The 2015 drought in Washington State: A harbinger of things to come? Environmental Research Letters 12:114008.

Mathewson, P. D., L. Moyer-Horner, E. A. Beever, N. J. Briscoe, M. Kearney, J. M. Yahn, and W. P. Porter. 2017. Mechanistic variables can enhance predictive models of endotherm distributions: the American pika undercurrent, past, and future climates. Global Change Biology 23:1048-1064.

McArthur, A. J. 1991. Thermal radiation exchange, convection and the storage of latent heat in animal coats. Agricultural and Forest Meteorology 53:325-336.

McArthur, A. J., and J. C. Ousey. 1996. The effect of moisture on the thermal insulation provided by the coat of a thoroughbred foal. Journal of Thermal Biology 21:43-48.

Millar, J. S. 1974. Success of reproduction in pikas, Ochotona princeps (Richardson). Journal of Mammalogy 55:527-542.

Millar, C. I., D. L. Delany, K. A. Hersey, M. R. Jeffress, A. T. Smith, K. J. Van Gunst, and R. D. Westfall. 2018. Distribution, climatic relationships, and status of American pikas (Ochotona princeps) in the Great Basin, USA. Arctic, Antarctic, and Alpine Research 50:e1436296.

Millar, C. I., R. D. Westfall, and D. L. Delany. 2014. Thermal regimes and snowpack relations of periglacial talus slopes, Sierra Nevada, California, U.S.A. Arctic, Antarctic, and Alpine Research 46:483-504.
Mizukami, N., and S. Perica. 2008. Spatiotemporal characteristics of snowpack density in the mountainous regions of the western United States. Journal of Hydrometeorology 9:14161426.

Monteith, J. L. 1965. Evaporation and environment. Pages 205234 in C. E. Fogg, editor. The state and movement of water in living organisms. Cambridge University Press, Cambridge, UK.

Morán-Ordóñez, A., N. J. Briscoe, and B. A. Wintle. 2018. Modelling species responses to extreme weather provides new insights into constraints on range and likely climate change impacts for Australian mammals. Ecography 41:308-320.

Moreno, J., and A. P. Møller. 2011. Extreme climatic events in relation to global change and their impact on life histories. Current Zoology 57:375-389.

Morrison, S. F., and D. S. Hik. 2007. Demographic analysis of a declining pika Ochotona collaris population: linking survival to broad-scale climate patterns via spring snowmelt patterns. Journal of Animal Ecology 76:899-907.

Morrison, S. F., and D. S. Hik. 2008. When? Where? And for how long? Census design considerations for an alpine lagomorph, the collared pika (Ochotona collaris). Pages 103-113 in P. Alves, N. Ferrand, and K. Hackländer, editors. Lagomorph biology: evolution, ecology and conservation. Springer-Verlag, Berlin, Germany.

Morrison, S. F., G. Pelchat, A. Donahue, and D. S. Hik. 2009. Influence of food hoarding behavior on the over-winter survival of pikas in strongly seasonal environments. Oecologia 159:107-116

Mote, P. W., A. F. Hamlet, M. P. Clark, and D. P. Lettenmaier. 2005. Declining mountain snowpack in western North America. Bulletin of the American Meteorological Society 86:3949.

Mote, P. W., D. E. Rupp, S. Li, D. J. Sharp, F. Otto, P. F. Uhe, M. Xiao, D. P. Lettenmaier, H. Cullen, and M. R. Allen. 2016. Perspectives on the causes of exceptionally low 2015 snowpack in the western United States. Geophysical Research Letters 43:10980-10988.

Mote, P. W., et al. 2003. Preparing for climatic change: the water, salmon, and forests of the Pacific Northwest. Climatic Change 61:45-88.

Nakagawa, S., P. C. D. Johnson, and H. Schielzeth. 2017. The coefficient of determination $R^{2}$ and intra-class correlation coefficient from generalized linear mixed-effects models revisited and expanded. Journal of the Royal Society Interface 14:20170213.

NRCS. 2017. SNOTEL temperature and snow pack snow water equivalent data stations located in Washington. https://www. wcc.nrcs.usda.gov/

Ockendon, N., et al. 2014. Mechanisms underpinning climatic impacts on natural populations: altered species interactions are more important than direct effects. Global Change Biology 20:2221-2229.

Oren, R., J. S. Sperry, G. G. Katul, D. E. Pataki, B. E. Ewers, N. Phillips, and K. V. R. Schäfer. 1999. Survey and synthesis of intra- and interspecific variation in stomatal sensitivity to vapour pressure deficit. Plant, Cell and Environment 22:1515-1526.

Pauli, J. N., B. Zuckerberg, J. P. Whiteman, and W. Porter. 2013. The subnivium: a deteriorating seasonal refugium. Frontiers in Ecology and the Environment 11:260-267.

Penczykowski, R. M., B. M. Connolly, and B. T. Barton. 2017. Winter is changing: trophic interactions under altered snow regimes. Food Webs 13:80-91.

R Core Team. 2017. R: a language and environment for statistical computing. R Foundation for Statistical Computing, Vienna, Austria. https://www.R-project.org/ 
Rehnus, M., K. Bollmann, D. R. Schmatz, K. Hackländer, and V. Braunisch. 2018. Alpine glacial relict species losing out to climate change: the case of the fragmented mountain hare population (Lepus timidus) in the Alps. Global Change Biology 24:3236-3253.

Riddell, E. A., E. K. Apanovitch, J. P. Odom, and M. W. Sears. 2017. Physical calculations of resistance to water loss improve predictions of species range models. Ecological Monographs 87:21-33.

Rodhouse, T. J., E. A. Beever, L. K. Garrett, K. M. Irvine, M. R. Jeffress, M. Munts, and C. Ray. 2010. Distribution of American pikas in a low-elevation lava landscape: conservation implications from the range periphery. Journal of Mammalogy 91:1287-1299.

Russello, M. A., M. D. Waterhouse, P. D. Etter, and E. A. Johnson. 2015. From promise to practice: pairing non-invasive sampling with genomics in conservation. PeerJ 3:e1106.

Schwalm, D., C. W. Epps, T. J. Rodhouse, W. B. Monahan, J. A. Castillo, C. Ray, and M. R. Jeffress. 2016. Habitat availability and gene flow influence diverging local population trajectories under scenarios of climate change: a place-based approach. Global Change Biology 22:1572-1584.

Sergio, F., J. Blas, and F. Hiraldo. 2018. Animal responses to natural disturbance and climate extremes: a review. Global and Planetary Change 161:28-40.

Sherwood, J. A., D. M. Debinski, P. C. Caragea, and M. J. Germino. 2017. Effects of experimentally reduced snowpack and passive warming on montane meadow plant phenology and floral resources. Ecosphere 8:e01745.

Smith, A. T., and B. L. Ivins. 1984. Spatial relationships and social organization in adult pikas: a facultatively monogamous mammal. Ethology 66:289-308.

Smith, A. T., W. Li, and D. S. Hik. 2004. Pikas as harbingers of global warming. Species 41:4-5.

Smith, A. T., and C. I. Millar. 2018. American pika (Ochotona princeps) population survival in winters with low or no snowpack. Western North American Naturalist 78:126-132.

Smith, A. T., and M. L. Weston. 1990. Ochotona princeps. Mammalian Species 352:1-8.

Stewart, J. A. E., J. D. Perrine, L. B. Nichols, J. H. Thorne, C. I. Millar, K. E. Goehring, C. P. Massing, and D. H. Wright.
2015. Revisiting the past to foretell the future: summer temperature and habitat area predict pika extirpations in California. Journal of Biogeography 42:880-890.

Stull, R. 2011. Meteorology for scientists and engineers. Third edition. The University of British Columbia, Vancouver, British Columbia, Canada.

Thornton, P. E., M. M. Thornton, B. W. Mayer, Y. Wei, R. Devarakonda, R. S. Vose, and R. B. Cook. 2017. Daymet: Daily surface weather data on a $1-\mathrm{km}$ grid for North America, version 3. ORNL DAAC, Oak Ridge, Tennessee, USA.

Varner, J., and M. D. Dearing. 2014a. Dietary plasticity in pikas as a strategy for atypical resource landscapes. Journal of Mammalogy 95:72-81.

Varner, J., and M. D. Dearing. 2014b. The importance of biologically relevant microclimates in habitat suitability assessments. PLoS ONE 9:e104648.

Wiens, J. J. 2016. Climate-related local extinctions are already widespread among plant and animal species. PLOS Biology 14:e2001104.

Williams, A. P., et al. 2013. Temperature as a potent driver of regional forest drought stress and tree mortality. Nature Climate Change 3:292-297.

Wingfield, J. C. 2013. The comparative biology of environmental stress: behavioural endocrinology and variation in ability to cope with novel, changing environments. Animal Behaviour 85:1127-1133.

Wunder, B. A. 1992. Morphophysiological indicators of the energy state of small mammals. Pages 83-104 in T. E. Tomasi and T. H. Horton, editors. Mammalian energetics: interdisciplinary views of metabolism and reproduction. Cornell University Press, Ithaca, New York, USA.

Yandow, L. H., A. D. Chalfoun, and D. F. Doak. 2015. Climate tolerances and habitat requirements jointly shape the elevational distribution of the American pika (Ochotona princeps), with implications for climate change effects. PLoS ONE 10: e0131082.

Zhang, Q., S. Manzoni, G. Katul, A. Porporato, and D. Yang. 2014. The hysteretic evapotranspiration-vapor pressure deficit relation. Journal of Geophysical Research: Biogeosciences 119:125-140

\section{SUPPORTING INFORMATION}

Additional supporting information may be found in the online version of this article at http://onlinelibrary.wiley.com/doi/ 10.1002/ecy.2638/suppinfo

\section{Data Availability}

Data are available from ScienceBase: https://doi.org/10.5066/p9ilp43h 